\title{
Primer Design and in silico Analysis of Endoglucanase Gene for Bacillus genus
}

\author{
Dewi Yuliani, $^{\text {a)* }}$ and Akyunul Jannah ${ }^{\text {b) }}$ \\ ${ }^{1}$ Chemistry Department, Faculty of Science and Technology Universitas Islam Negeri Maulana \\ Malik Ibrahim Malang Jln Gajayana No. 50 Malang, Indonesia \\ ${ }^{a)}$ Corresponding author: dewi.yuliani@kim.uin-malang.ac.id \\ b)akyunul_jannah2007@yahoo.com
}

\begin{abstract}
Endoglucanase is an enzyme initiating hydrolysis of cellulose. The enzyme has been applied in various fields, such as medicine and food. Previous research has been isolated cellulolytic bacteria that are capable to produce endoglucanase, i.e. Bacillus brevis and Bacillus cereus from bekatul. Determination of bacterial isolate capability to produce endoglucanase can be conducted by gene detection. The detection method involves PCR using a universal designed primer to amplify the targeted gene. The aim of study was to design primers which amplify endoglucanase gene. The steps involved collecting data through NCBI, multiple sequence alignment using MUSCLE, design primer, in silico PCR and primer characteristics checking. Primer was designed by online program and literature. Template for primer design was Bacillus sp. (LN680001) consisting of $1500 \mathrm{bp}$. Primer design used three kinds of online program, i.e. Primer3plus, Primerquest tool, and primer BLAST. Every program resulted different length of product. Primer3plus and Primerquest tool produced 1124-1209 bp and 225-534 bp of product length, while primer BLAST produced 1403$1451 \mathrm{bp}$ of product length. Primer based online program could not isolated endoglucanase gene completely. Based on literature study, primer CelF and CelR has been isolated endoglucanase gene, $1500 \mathrm{bp}$. Analysis result showed literature studied primer produce length of product longer than online program primer. Primer endoglucanase gene was obtained 5' ATGAAACGGTCAATCTC for primer forward and 5' CTAATTTGGTTCTGTTCCC for primer reverse. Prediction of primer characterization based on annealing temperature, $41.2-42.1^{\circ} \mathrm{C}$, and percentage of GC $46.3-48.1 \%$. In silico PCR amplification analysis showed that primer proved specific to amplify the endoglucanase gene from Bacillus genus to produce complete gen, $1500 \mathrm{bp}$.
\end{abstract}

Keywords: design primer, in silico, endoglucanase gene, Bacillus

\section{INTRODUCTION}

Endoglucanase (EC 3.2.1.4) is a part of cellulose enzyme complex initiating cellulose hydrolysis process. The enzymes has function to degrade $\beta$-1,4-glikosidic bond specifically and produce short chain of cellulose $(1,2)$. Endoglucanase was applied widely in various industries, such as brewing industry (3), biofuel (4), detergen (5) and animal feed (6). Other application endoglucanase are pharmaceutical industry, such as enzyme was used as therapy agent(7, 8, 9, 10).

Endoglucanse was produced for varied microorganism, including fungi and bacteria. Endoglucanase from bacteria is easier to isolate than from fungi (11). Bacillus is one of bacteria genus that capableto produce this enzyme, e.g. B. cereus, B. licheniformis, B. subtilis, B. plymixa, B. amylolyquefaciens, B. pumilus, B. circulansand B. flexus $(12,13,14)$. Previous research has been 
isolated bacteria producing endoglucanase from bekatul. Based on phenotypic identification, the bacteria were B. Brevis \& B. cereus.

Exploration bacteria producing endoglucanase has been conducted. To study bacteria producing endoglucanase detailed is better start with the gene. Endoglucanase gene consists of $1500 \mathrm{bp}$ approximately. Ozaki et al. (1991) and Han, et al. (1995), endoglucanase coding gene is 1389 and 1461, respectively. Isolation endoglucanase gene generally done by PCR method with certain primer. In this study, will be search primer to isolate endoglucanase gene by in silico approach and based on literature study.

\section{MATERIALS AND METHODS}

\section{Instruments and Materials}

Instruments used in this study were bioinformatics software online and offline for design primer, e.g. BioEdit, Primer3plus (http://www.bioinformatics.nl/cgi-bin/primer3plus/primer3plus.cgi/), Primerquest tool (http://sg.idtdna.com/Primerquest/Home/Index), Primer BLAST (https://www.ncbi.nlm.nih.gov/tools/primer-blast/), online OligoAnalyzer Tool (https://sg.idtdna.com/calc/analyzer), in silico PCR amplification (http://insilico.ehu.eus/PCR/), and Toshiba Laptop Satelite L745. The material used in this research was DNA sequence data of endoglucanase partial and complete gene from Bacillus genus downloaded in FASTA format from NCBI database.

\section{Collecting Data}

Endoglucanase genes were downloaded from GenBank web, NCBI (http://www.ncbi.nlm.nih.gov/genbank/). Endoglucanase genes partially and completely were from various Bacillus genus. Compiled endoglucanase gene sequences data was analyzed by MUSCLE in Bioedit program. From the analysis will be chosen one complete sequence as template to design primer $(15,16)$.

\section{Primer Design}

Primer was design using online software programs, e.g. Primer3plus, Primerquest tool, and Primer BLAST. Based three online programs resulted some pair primers with different length (15, 16).

\section{Data Analysis}

Primer designed was checked by in silico PCR amplification. Characteristic primer was analysis by online OligoAnalyzer Tool. The application examined the value of Tm (melting temperature) and GC ratio. 


\section{RESULTS AND DISCUSSION}

Endoglucanse gene sequences data downloaded from NCBI database were presented in Table 1. There are fourteen gene sequences from various strain Bacillus, e.g. B. subtilis, B. amyloliquefaciens, and $B$. megaterium. The sequences are full gene and have high homology. Bacillus sp. was used as template, LN680001, to design primer endoglucanase gene.

TABLE 1.Endoglucanase gene sequence data mining

\begin{tabular}{|c|c|c|}
\hline Strain Bacillus & Accesion number & Sequence Length \\
\hline B. subtilis IARI-SP-1 & KF240847 & 1500 \\
\hline B. amyloliquefaciens IARI-SP-2 & KF240848 & 1500 \\
\hline B. megaterium IARI-SP-9 & KF240851 & 1500 \\
\hline B. amyloliquefaciens PSM 3.1 & GU390463 & 1500 \\
\hline B. subtilis shu-3 & HM470252 & 1500 \\
\hline B. subtilis & AY044252 & 2589 \\
\hline B. subtilis $168 \operatorname{trpC} 2$ & Z29076 & 1800 \\
\hline B. subtilis & X04689 & 2435 \\
\hline B. subtilisJA18 & DQ116829 & 1500 \\
\hline B. subtilis $\mathrm{BS}-2$ & EU022560 & 1500 \\
\hline B. subtilis subsp. subtilis 168 & NC_000964 & 1500 \\
\hline B. subtilis & D01057 & 1928 \\
\hline B. subtilis & X67044 & 2314 \\
\hline Bacillus sp. & LN680001 & 1500 \\
\hline
\end{tabular}

Bacillus sp. as template was analyzed by three online design primer programs, e.g. Primer3plus, primerquest tool, and primer BLAST. Based on Primer3plus and primerquest tool were resulted five pair primers every program with various lengths. Primer3plus and primerquest tool resulted product length, 1124-1209 bp and 225-534 bp, respectively. Primer BLAST program produced ten pair primer with product length $1403-1450 \mathrm{bp}$. The longest product of each program was shown in Table 2.

TABLE 2. Pair Primer from online Primer design program

\begin{tabular}{lllc}
\hline \multicolumn{1}{c}{ Program } & & \multicolumn{1}{c}{ Primer $\left(\mathbf{5}^{\prime} \rightarrow \mathbf{3}^{\prime}\right)$} & Product length \\
\hline Primer3plus & Fx & GGTACAGCTGAAGGGGATCA & 1209 \\
& Rx & TCATTGTGAAGACGGAGCTG & 534 \\
Primerquest tool & Fy & ATGGAGCCAGGATGTGAATG & \\
& Ry & ACCGTGGTATTGCCGTTATT & 1450 \\
Primer BLAST & Fz & CGTTATTGACAATGGGCGGC & \\
& Rz & GGTTCTGTTCCCCAATCAGT & \\
\hline
\end{tabular}

Based on Table 2, the longest product from primer BLAST was compared to primer form literature studied. Primer from literature studied has proved to isolate endoglucanase gene successfully. Product amplicon from both primer were $1311 \mathrm{bp}$ for EN1F-EN1R primer and 1500 bp for CelF-CelR primer. It can be concluded that primer CelF and CelR can isolate endoglucanase gene completely. Primer annealing on the template was predicted in Fig. 1. 
TABLE 3. Primer ofendoglucanase gene from literature

\begin{tabular}{clcc}
\hline No & & \multicolumn{1}{c}{ Primer } & References \\
\hline 1 & EN1F & 5' CCAGTAGCCAAGAATGGCCAGC & $(17)$ \\
& EN1R & 5' GGAATAATCGCCGCTTTGTGC & \\
2 & CelF & 5' ATGAAACGGTCAATCTC & $(1)$ \\
& CelR5 & CTAATTTGGTTCTGTTCCC & \\
\hline
\end{tabular}

>gi|724425628:1958638-1960137 Bacillus sp. genome assembly BS34ACh, chromosome : I

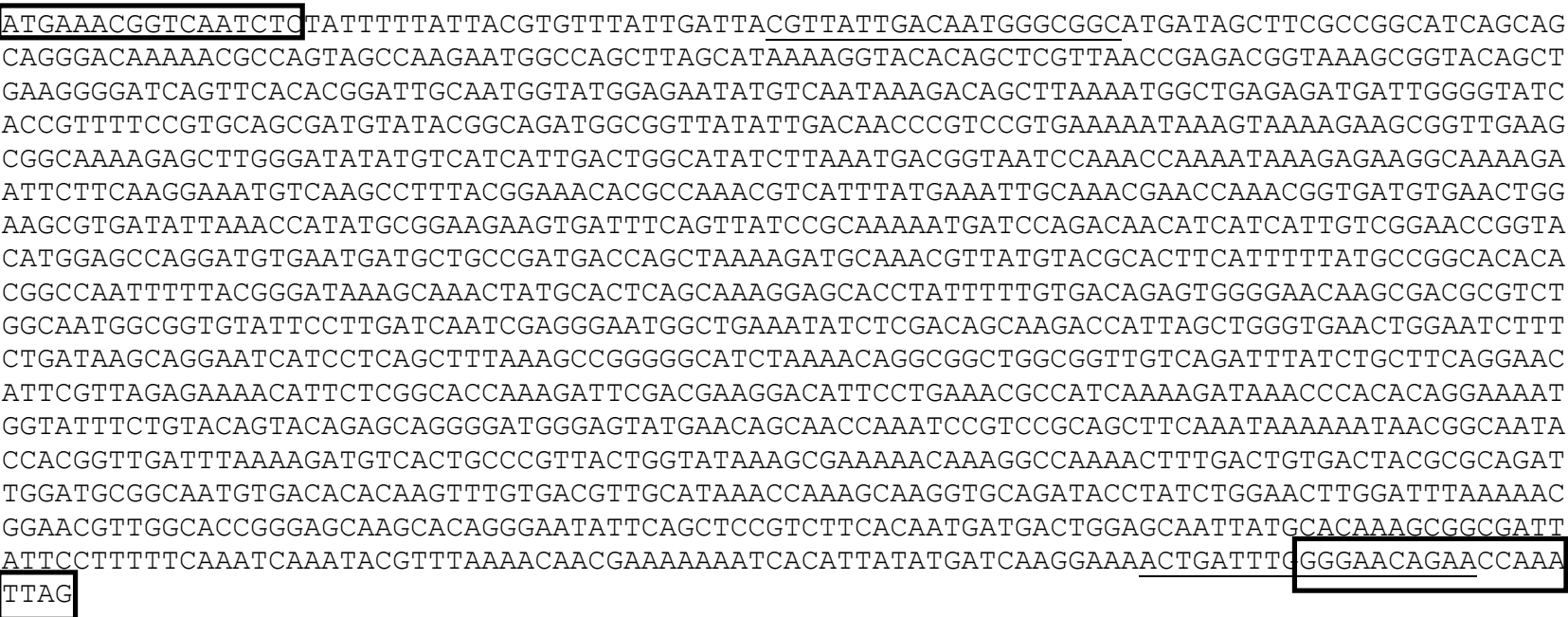

FIGURE 1. Prediction of annealling primer of Fz-Rz and CelF-CelR based on LN680001 template. Fz-Rz primer was indicated by underline letther, while CelF-CelR was indicated by box letter

Both primers were checked by by in silico PCR amplificatioin. Fz-Rz primer gave no result, while CelF-CelRprimer gave a 1500 product. The product shown a band only for $B$. amyloliquifaciens and B. subtilis. Characteristic primer based on Oligoanalyzer tools shown annealing temperature and $\mathrm{GC}$ rasio. Characterization annealing temperature and $\mathrm{GC}$ rasio each primer respectively was $46.3^{\circ} \mathrm{C}$ and $41.2 \%$ for CelF, and $48.2^{\circ} \mathrm{C}$ and $42.1 \%$ for CelR.

\section{CONCLUSION}

Endoglucanase gene from Bacillus genus can be isolated using primer CelF, 5'ATGAAACGGTCAATCTC for forward, and CelR, 5' CTAATTTGGTTCTGTTCCC for reverse.

\section{References}

1. Nurachman, Z.,Kurniasih, S.D., Puspitawati, F., Hadi, S., Radjasa and Natalia, D. 2010. American Journal of Biochemistry and Biotechnology6(4), 268-274 (2010).

2. Pham, T.H., Quyen, D.T., Nghiem, N.M., and Vu, T.D. Journal of Microbiology and Biotechnology21(10), 1012-1020 (2011).

3. Celestino, K.R.S., Cunha, R.B., and Felix, C.R.BMC Biochem7, 23 (2006)

4. Yennamalli, R.M., Rader, A.J., Kenny, A.J., Wolt, J.D., andSen, T.Z. Biotechnology for biofuel6(136) (2013).

5. Shimonaka, A., Koga, J., Baba, Y., Nishimura, T., Murashima, K., Kubota, H., and Kono, T.Bioscience Biochemistry 70 (4),1013-1016 (2006). 
6. Kundu, A., Karmakar, M., danRaym, R.R. International Journal of Recycling of Organic Waste in Agriculture1(13) (2012).

7. Kawai, Y., Noda, S., Ogino, C., Takeshima, Y., Okai, N., Tanaka, T., and Kondo, A. Microbial Cell Factories12(45) (2013).

8. Huang, S., Deng, G., yang, Y., Wu, Z., and Wu, L. Agriculture, Agribusiness and Biotechnology58(5) (2015).

9. Kim, et.al. Asian-Australasian Journal of Animal Science29(1), 126-133 (2016).

10. Vellard, M. Current Opinion in Biotechnology 14, 444-450 (2003).

11. Aftab, S., Aftab, M.N., Haq, I.U., Javed, M.M., Zafar, A., and Iqbal, I. African Journal of Biotechnology11(12), 2846-2854 (2012).

12. Han, S.J., Yoo, Y.J., and Kangs, H.S. The Journal of Biological Chemistry270(43), 2601226019 (1995).

13. Kuhad, R.C., Gupta, R. and Singh, A. Enzyme Research, doi: 10.4061/2011/280696 (2011).

14. Nirmala, P., danSindhu, A. International Journal of Applied Engineering Research2(2), 472481 (2011).

15. Kamel A. Abd-Elsalam. African Journal of biotechnology2(5), 91-95 (2003)

16. Nugroho, I. B. and Handayani, N.S.N. AIP Conference Proceedings 1755, 140007 (2016).

17. Ashe, S., Maji, U.J., Sen, R., Mohanti, S., and Maiti, N.K. 3 Biotech4, 461-465 (2014). 